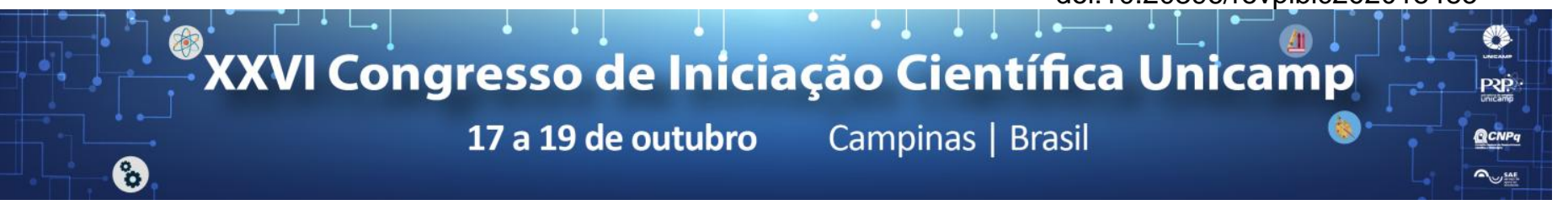

\title{
Discussão sobre Mosaicos de Unidades de Conservação a partir do Estudo de Caso Juréia- Itatins.
}

\section{Gabriel de Oliveira Quintana*, Rafael Costa Freiria.}

\section{Resumo}

Realizou-se a análise da concepção de Mosaico de Unidades de Conservação (MUC), regulamentado pela Lei № 9.985/2000, que instituiu o Sistema Nacional de Unidades de Conservação (SNUC), avaliando os benefícios, oportunidades e desafios para a sua implementação, considerando as diversas variáveis envolvidas, bem como a busca por maior efetividade desse modelo de gestão de Unidades de Conservação (UCs), por meio do estudo de caso do Mosaico de Unidades de Conservação Juréia-Itatins (MUCJI), localizado no litoral sul do estado de São Paulo.

\section{Palavras-chave:}

Mosaico de Unidades de Conservação, Juréia-Itatins, Legislação Ambiental.

\section{Introdução}

O projeto tem como objetivo a análise da concepção de Mosaico de Unidades de Conservação, instrumento previsto pelo SNUC, a partir do Estudo de Caso JuréiaItatins, utilizando referenciais teóricos, legislações, documentos e informações existentes relacionadas com o tema, discutindo sobre os desafios atuais dos MUCs a partir dos estudos realizados para a situação da JuréiaItatins e propondo soluções voltadas para uma maior efetividade na implantação e gestão de MUCs.

A figura organizacional Mosaico é abordada no cap. IV, artigo 26 da Lei SNUC. Na existência de um conjunto de UCs de categorias diferentes ou não, próximas, justapostas ou sobrepostas, além de outras áreas protegidas públicas ou privadas, formando um Mosaico, a gestão do conjunto terá que ser realizada de forma integrada e participativa, mantendo os objetivos de cada UC, compatibilizando a presença da biodiversidade local, a valorização da sociodiversidade e o desenvolvimento sustentável (BRASIL, 2000).

O MUCJI é regulamentado pela Lei № 14.982, de 08 de abril de 2013 do Estado de São Paulo, sendo composto pela Estação Ecológica da Juréia-Itatins, pelos Parques Estaduais do Itinguçu e do Prelado, pelas Reservas de Desenvolvimento Sustentável do Espraiado e da Barra do Una, e pelo Refugio Estadual de Vida Silvestre do Abrigo e Guararitama (SÃO PAULO, 2013).

\section{Resultados e Discussão}

As UCs que compõem o MUCJI foram criadas com 0 objetivo de assegurar na região a conservação e proteção da biodiversidade, juntamente com 0 desenvolvimento sustentável, conectividade entre as UCs e a valorização da sociodiversidade, através de uma gestão integrada e participativa de um território de grande relevância ambiental, marcado por disputas territoriais e divergências de interesses dos seus moradores e populações tradicionais. Além disso, o arcabouço legislativo que até antes da oficialização do mosaico insidia sobre o território, contribui para a perda de efetividade na proteção e conservação do meio ambiente, além da garantia dos direitos das populações tradicionais residentes, gerando consequências presentes para a gestão atual do MUCJI (PIEDADE, 2016).

Deste modo, por meio dos objetivos e estratégias para a constituição de um MUC de acordo com a base legal, foi realizado um diagnóstico destes fatores perante 0 cenário atual do MUCJI, sendo possível identificar fragilidades relacionadas ao Plano de Manejo do Mosaico, ao Conselho Gestor, ao desenvolvimento e fortalecimento da identidade territorial, além da resolução e gestão de conflitos com históricos passados no território. Este confronto entre a expectativa de um MUC com a realidade do MUCJI permitiu identificar os desafios para os MUCs e propor soluções para uma maior implantação e gestão.

Figura 1. Mosaico de Unidades de Conservação JuréiaItatins (SP).

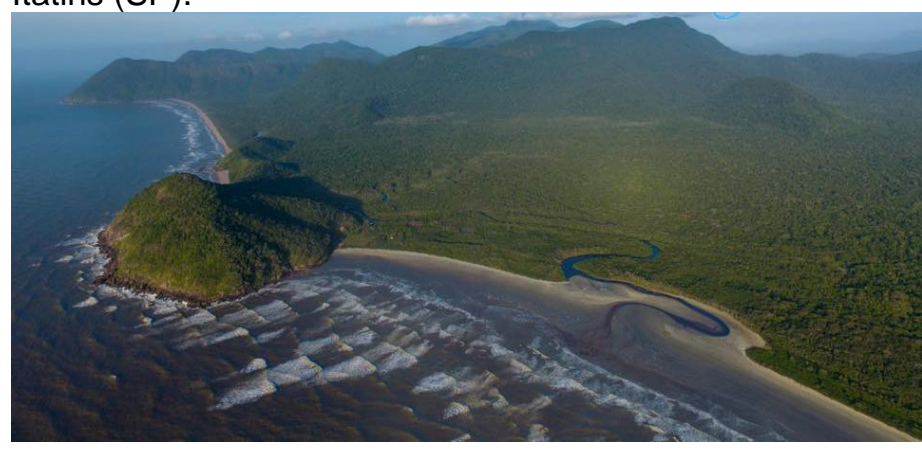

\section{Conclusões}

Os MUCs representam uma inovação na busca pela gestão integrada e participativa, considerando os objetivos de cada UC em um contexto que abrange fatores ambientais, econômicos e socioculturais. Porém, para que o MUC seja implementado e efetivo em suas funções, deve haver uma integração coesa entre o direito e a gestão ambiental, desenvolvendo ações que consolidem o Mosaico em seus diversos âmbitos.

\section{Agradecimentos}

Os autores agradecem ao Instituto Ernesto Zwarg (IEZ) por possibilitar duas visitas técnicas ao MUCJI, ao SAE/UNICAMP pela bolsa concedida e ao Professor Doutor Vitor Eduardo Molina Júnior, pelo auxílio na realização de um mapa temático.

BRASIL. Lei $\mathbf{N}^{\mathbf{0}} \mathbf{9 . 9 8 5}$, de 18 de julho de 2000. 2000

SÃO PAULO. Lei $\mathbf{N}^{\circ} \mathbf{1 4 . 9 8 2}$, de 08 de abril de 2013. 2013

FREIRIA, Rafael Costa. Direito, gestão e políticas públicas ambientais. Editora SENAC São Paulo, 2011.

PIEDADE, Flávia Lordello; MOLINA, Silvia Maria Guerra. Proteção jurídica ambiental da Jureia: desafios para a efetiva aplicação e eficácia da legislação ambiental. Unisanta BioScience, v. 5, n. 1, p. 12-26, 2016. 